Article

\title{
The Relationship between Urban Sprawl and Farmland Displacement in the Pearl River Delta, China
}

\author{
Shiqiang Du ${ }^{1,2,3}$, Peijun Shi ${ }^{1, *}$ and Anton Van Rompaey ${ }^{2}$
}

1 State Key Laboratory of Earth Surface Processes and Resources Ecology, Beijing Normal University, No. 19 Xinjiekouwaidajie Street, Beijing 100875, China;

E-Mail: geo.dushiqiang@gmail.com

2 Geography Research Group, Department of Earth and Environmental Sciences, Katholieke Universiteit Leuven, Celestijnenlaan 200E, Heverlee 3001, Belgium;

E-Mail: Anton.VanRompaey@ees.kuleuven.be

3 Department of Geography, Shanghai Normal University, Guilin Road 100, Shanghai 200234, China

* Author to whom correspondence should be addressed; E-Mail: spj@bnu.edu.cn;

Tel.: +86-10-5880-8179; Fax: +86-10-5880-2158.

Received: 21 October 2013; in revised form: 5 December 2013 / Accepted: 20 December 2013 / Published: 27 December 2013

\begin{abstract}
China is rapidly urbanizing and will inevitably face trade-offs between promoting economic growth through further urbanization and protecting fertile farmland against accelerated urban expansion. This paper presents how this dilemma is being addressed in one of the most rapidly urbanizing regions in China, the Pearl River Delta (PRD), by means of assessing urban growth and farmland dynamic, as well as their complex relationships. Land use maps derived from Landsat imagery for 1990, 2000 and 2010 show a process of accelerated urban sprawl whereby built-up lands have more than quadrupled and scattered centers have merged into megacities. Nonetheless, the land use efficiency is considerably low and is declining relative to Hong Kong and Macau with respect to urban population density. On the other hand, the spreading of urban areas on farmlands causes new farmland reclamation and accelerated deforestation in the hilly surroundings. In addition, the displaced farmlands do not ensure food production because of both reclaiming farmlands on infertile lands and diversifying farming activities from grain production to market-oriented ones. The accelerated urbanization and farmland displacement are driven by profit-oriented development strategy and ineffective land use planning. Our findings demonstrate how spatial analysis can help to investigate the integrated effects of land policies on landscape.
\end{abstract}


Keywords: urban sprawl; landscape index; farmland protection; spatial analysis

\section{Introduction}

Accelerated urbanization has been viewed as an important instrument for promoting economic development and reducing regional wealth disparities in some developing countries [1,2]. Nevertheless, the literature has brought forward a wide range of negative effects pertaining to the human-environment system in sprawled urban areas [3]. A frequent conflict exists between urban expansion and farmland protection, because urban expansion is unavoidably at the expense of clearing surrounding fertile farmlands, which were once fundamental to the city's agricultural market. To protect farmland and open space many developed countries have already adopted various measures, including farmland protection [4,5], smart conservation [6], greenway [7], green infrastructure [8] and market oriented policies [9]. However, in the developing world, not only are such strategies unimplemented, but the problem itself is also more pressing as this is where the increase in global urban population is concentrated [10,11].

Developing countries are experiencing an accelerated urbanization [10]. Their cities will probably hold more than $95 \%$ of the net increase in global population by 2050 [11]. In China, the world's second-largest economy and currently the most populous developing country, the urban population has increased by 500 million during 1980-2011 that exceeds the total population in most countries. Its proportion in the total population has unbelievably risen from $19.6 \%$ to $51.3 \%[12,13]$. This trend will continue in the coming decades and by 2050, the number of urban dwellers will rise by another 300 million [11]. Without a doubt, existing urban areas will sprawl out and new urban centers will spring up to hold the growing dwellers. Farmlands are therefore at great risk of being developed without land use policy reformation.

Farmland loss in China receives a lot of attention because of concerns about how to feed the largest population in the world [14-18]. The Chinese central government made farmland protection an essential tool and enacted both the Basic Farmland Protection Regulation (BFPR) and the new Land Administration Law (LAL) in 1999 [19] to reduce farmland loss, ensure grain production and increase urban land use efficiency [17,18]. These policies require that local governments and individuals reduce the demand for new urban lands by using them more efficiently and ensure that development on farmlands is only allowed if their substitutes can be reclaimed elsewhere [20]. However, as land resource is significant in promoting economic growth in China, decision-makers are therefore conflicted about whether or not to implement them strictly at the cost of lowering economic benefit $[2,21]$.

Many studies found that the land policies only reduced the net loss of farmland through reclaiming farmlands in peripheral areas. Li [22] argued that the farmland protection policy could give rise to reclaiming new farmlands on less suitable areas of lower productivity. Liu et al. [17], and Liu et al. [23] analyzed satellite images of mainland China for 1990, 2000 and 2005. They found farmland decreased enormously in rapidly urbanized provinces whereas considerable farmlands were reclaimed in peripheral areas. Wang et al. [24] reached a similar conclusion based on the nation-wide 
survey data of land use change during 1996-2008. Moreover, Zhang et al. [25] also found farmland displacement in Foshan of the Pearl River Delta. Therefore, not only could the land policies ensure farmland stability to a certain extent but they could also cause farmland displacement as a by-product. Nevertheless, it is still unknown how this mechanism works at a regional scale.

On the other hand, studies also argued that current land policies were not capable of controlling urban expansion. Lichtenberg and Ding [19] conceptually analyzed the possible consequences of current land policies in the context of the institutional structure and argued that current policies could cause excessive farmland loss and inefficient land use in urban areas. Moreover, Lu and Huang [26] analyzed the survey data of urban lands during 1997-2008 and reported that rapidly expanding urban lands were far less than efficiently used. They found that the urban lands increased much faster than population did and a considerable amount of cleared farmlands lay idle for several years before any actual construction. Similarly, Wei and Zhao [27], and Tan et al. [28] argued that the current land policies caused over-consumption of farmland compared with a competitive market situation based on case studies in Guangzhou and Yingtan, respectively. It therefore seems that the policies do not work as designed by the decision-makers and not succeed in controlling urban expansion.

At present, however, a spatial analysis of the impact of land policies on multiple land use changes remains to be elucidated in a metropolitan area. The above findings were mainly based on the national level studies [17,18,23,24] except some cases of individual municipalities or counties [25,27-29]. Moreover, it is still unclear how the conflict between increasing urbanization for economic development and protecting farmland against urban sprawl is addressed. It is therefore necessary to compare the land use changes before and after the enacting of the main policies in 1999. It would be more reliable to compare the land use changes between areas that implemented the policies in mainland China and other areas with independent policies and planning system, such as Hong Kong and Macau. Fortunately, Remote Sensing methods can facilitate such a study. Among the remote sensing datasets, Landsat imagery is a relative high resolution satellite dataset and has produced an uninterrupted multispectral record of the land surface since 1972 [17,30]. It thus can play critical role in mapping the land use conditions and analyzing the temporal and spatial land use variation.

We mainly aim to investigate the changes in regional landscape both qualitatively and quantitatively in the context of current land policies. Taking as an example the Pearl River Delta (PRD), one of the most rapidly urbanized areas in China [2,31-33], we employed Landsat datasets and spatial analysis to answer the following questions: (1) How does the landscape change in the context of rapid urbanization? (2) Is there connection between urban expansion and the changes in other land use types? (3) How do stakeholders respond to the trade-offs between economic growth and farmland protection?

\section{Materials and Methods}

\subsection{Study Area}

In this study, the Pearl River Delta (PRD) refers to an emerging metropolitan area of 45,000 $\mathrm{km}^{2}$ on the southern coast of China. It is composited by nine municipalities of Guangdong province including Guangzhou and Shenzhen (Figure 1). Hong Kong and Macau, the two Special Administrative Regions 
(SAR) of China, are also included for contrast analysis of the land policies, as they border the PRD area but have independent policy system from the mainland China. The PRD area has a semi-tropical monsoon climate, with an average annual rainfall of $1,754 \mathrm{~mm}$ and mean temperature of $22{ }^{\circ} \mathrm{C}$. The humid climate combined with rich alluvial soils supports two or three crops a year that once made the PRD an important production base for rice, sugar cane and tropical fruits. As a result, farmlands and rural landscape dominated the delta until the region was opened for foreign investment and a free market policy was installed in the late 1970s. Thereafter, however, the PRD has become one of the major hubs of China's economic growth and one of the most rapidly urbanized city-clusters in the world. The PRD had 56 million permanent residents and produced a GDP of $\$ 580$ billion in 2010 . Consequently, it has been among the most densely urbanized regions in China and has experienced significant decrease of farmland [15,34].

Figure 1. The Pearl River Delta (PRD) area.

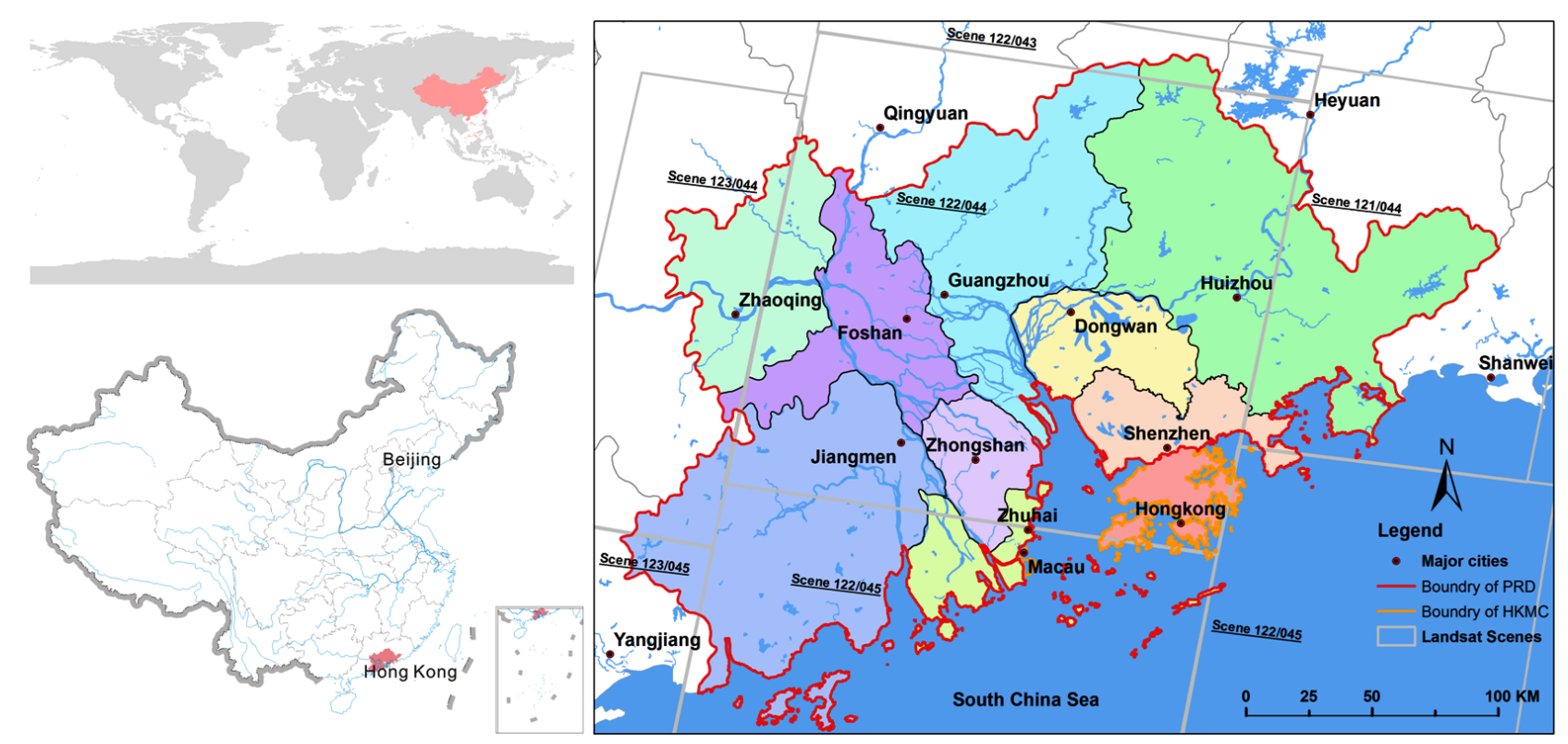

\subsection{Land Use Detection}

Landsat (Land Satellite) imagery was employed to create the land use maps for 1990, 2000 and 2010. Landsat imagery is available since 1972 from six satellites in the Landsat series: MSS (Multi-spectral Scanner), TM (Thematic Mapper), and ETM+ (Enhanced Thematic Mapper Plus), which have been a major component of NASA's Earth observation program. Landsat supplies high resolution imagery for free that is available through the Global Land Cover Facility (GLCF) at Maryland University and the United States Geological Survey (USGS). In this study, both the images and the created maps had a resolution of 30-m. The Landsat images were mapped in Figure 1 and described in more detail in Table 1. In collecting images through the USGS, a maximal deviation of one year from the three baseline years was allowed to accommodate image shortage. Exceptions on this rule were made for the images of 1990 where an image of 1993 and an image of 1995 were used avoid cloud cover in the north (Scene: path 122/row 043) and in the south of the study area (Scene: path 122/row 045), respectively. Since the two images only covered a limited and peripheral part of the study area, they were not considered to have significant impact on the results of the analysis. 
Table 1. List of Landsat images for land use detection in the PRD.

\begin{tabular}{ccccccc}
\hline \multirow{2}{*}{ Path/Row } & \multicolumn{1}{c}{$\mathbf{1 9 9 0}$} & \multicolumn{2}{c}{$\mathbf{2 0 0 0}$} & \multicolumn{2}{c}{$\mathbf{2 0 1 0}$} \\
\cline { 2 - 7 } & Date & Sensor & Date & Sensor & Date & Sensor \\
\hline $121 / 044$ & 9 October 1991 & TM & 27 January 2000 & ETM+ & 11 January 2009 & TM \\
$121 / 045$ & 20 November 1989 & TM & 26 December 1999 & ETM+ & 14 January 2010 & TM \\
$122 / 043$ & 05 October 1993 & TM & 14 September 2000 & ETM+ & 2 November 2009 & TM \\
& 13 October 1990 & TM & 1 November 2000 & ETM+ & 2 November 2009 & TM \\
$122 / 044$ & 24 December 1990 & TM* & 14 September 2000 & ETM+ & & TM \\
$122 / 045$ & 30 December 1995 & TM & 1 November 2000 & ETM+ & 2 November 2009 & TM \\
$123 / 044$ & 21 September 1991 & TM & 27 November 2001 & ETM+ & 9 January 2009 & TM \\
& 11 February 1989 & TM* & & & & \\
$123 / 045$ & 2 January 1990 & TM & 8 December 1999 & ETM+ & 9 January 2009 & TM \\
\hline
\end{tabular}

Note: TM* represents Landsat 4 TM; TM refers to Landsat 5 TM; ETM+ is Landsat 7 ETM+.

Table 2. Land use categories and its characters.

\begin{tabular}{|c|c|c|}
\hline Category & Description & Picture \\
\hline Built up & $\begin{array}{l}\text { Paved areas, including the residential and commercial land, } \\
\text { industrial plants and transportation networks }\end{array}$ & 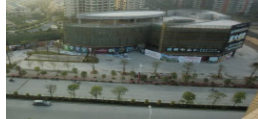 \\
\hline Idle land & Land prepared for new urban development & \\
\hline Water & Water-bodies that are not used for intensive aquaculture & \\
\hline Fishpond & $\begin{array}{l}\text { Water-bodies that are used for intensive aquaculture. It is often } \\
\text { combined with mulberry to comprise the Mulberry } \\
\text { Dike-Fishpond System (Zhong, 1982) }\end{array}$ & \\
\hline Forest & Wooded area with undergrowth & \\
\hline Farmland & Land use for dryland farming and paddy rice fields & \\
\hline Orchard & Fruit trees. & \\
\hline Grassland & Natural shrub and grasslands & \\
\hline
\end{tabular}

The gathered images produced the land use information with an 8-class scheme including built-up land and farmland (Table 2). However, the classification faced three main obstacles. First, the urban areas are heterogeneous [30] due to diverse materials used for man-made structures [35] and various building densities and heights; Second, the spectrum of vegetation is complex due to multiple plant types and densities and different irrigation and harvest seasons; Third, each land use map is based on a 
mosaic of at least seven Landsat images. In order to overcome these obstacles, a fixed procedure was developed which was shown in Figure 2.

Figure 2. Procedure for land use classification.

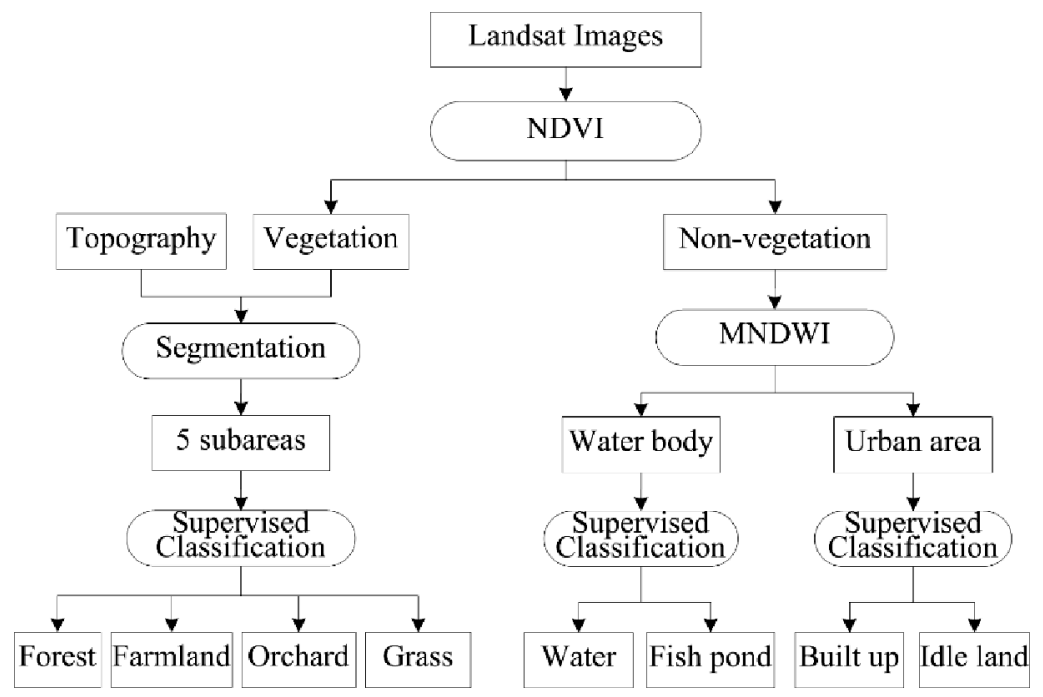

The procedure first detected three groups of land use classes, namely vegetation, water and urban areas by means of two quantitative indices of the Normalized Difference Vegetation Index (NDVI, Equation (1)) and the Modified Normalized Difference Water Index (MNDWI, Equation (2)) [36]. The thresholds of the two indices were interactively adapted by multiple researchers according to the acquisition season and the spectrum characteristics of the image concerned. Then, the procedure applied Supervised Classification based on Maximum Likelihood Clustering to separate the eight land use classes within the three predefined groups of "vegetation", "water bodies" and "urban area". To be specific, vegetation was identified firstly with higher NDVI value whereby the threshold value was around 0.08 and interactively adapted according to the image's condition, especially the acquisition season. Then, for the non-vegetation, MNDWI was used to extract water body from urban area whereby the threshold was set zero. Next, Supervised Classification was applied for water body and urban area to classify fishpond and water, and built-up land and idle land.

$$
\begin{gathered}
\text { NDVI }=\frac{\text { band } 4-\text { band } 3}{\text { band } 4+\text { band } 3} \\
M N D W I=\frac{\text { band } 2-\text { band } 5}{\text { band } 2+\text { band } 5}
\end{gathered}
$$

Finally, to classify the four types of vegetation, vegetation area was segmented before being applied the Supervised Classification. Image segmentation is a measure to divide the image into homogeneous sub-areas and to reduce the image's complexity [37]. It is very suitable to apply in vegetation classification because vegetation is often heterogeneous due to multiple plant types and densities, and different irrigation and harvest seasons. Meanwhile, topographic attributes play important role in determining vegetation distribution, and elevation, slope and aspect are the most relevant primary factors [38]. Thus, the vegetation area was segmented into five subareas according to the most relevant topographic factors (Table 3), and then in each subarea Supervised Classification was used to classify the four types of vegetation (Figure 2). 
Table 3. Spatial division for vegetation classification.

\begin{tabular}{cccc}
\hline \multirow{2}{*}{ Name } & \multicolumn{3}{c}{ Character } \\
\cline { 2 - 4 } & Elevation & Slope & Aspect \\
\hline Subarea 1 & $<20$ & & \\
Subarea 2 & $20-100$ & $<10$ & \\
Subarea 3 & $\geq 100$ & $<10$ & \\
Subarea 4 & $\geq 20$ & $\geq 10$ & $45-225$ \\
Subarea 5 & $\geq 20$ & $\geq 10$ & $<45$ or $\geq 225$ \\
\hline
\end{tabular}

The procedure was implemented by means of the software ERDAS 9.1. It first produced the land use map for 2010 and used it as a baseline for the other two maps. Next, it mapped for 2000 and 1990 in sequence with an additional rule limiting their built-up lands to the urban footprints of their respective subsequent period. This rule is based on the following ideas: (1) Integration of the classification result from 2010 into former classification time steps; and thus supporting the hypothesis that the urban areas grew constantly and built-up lands never disappeared [30]; (2) The classification accuracy for the urban areas of 2010 can be ensured relatively by the survey data that was conducted on 2009 and 2010 and the aerial photographs that taken on 2006. Then, the produced maps were manually corrected through Visual Interpretation and isolated pixels were eliminated from the results by means of a 3-by-3 majority filter to reduce the map complexity and remove random noise. Finally, their accuracies were assessed by a respective dataset of 256 validation points, which were derived randomly by the ERDAS 9.1. Those points were checked through field survey and Visual Interpretation of the aerial photographs and the Landsat images. The assessment was conducted independently by two researchers.

\subsection{Spatial Analysis}

Landscape metric is a useful tool for quantifying both composition and spatial configuration of changing landscape pattern [39]. However, it is often misused because interpreting is more difficult than calculating [40]. In this consideration, only the metrics of directly quantifying urban growth were employed to describe the urbanization process and its variation both temporally and spatially. Additionally, shape-related metrics were excluded because they can be significantly influenced by biophysical factors like elevation and slope. On the PRD scale, the total area (TA) of each land use type described the overall landscape change; the patch size distribution (PSD) of built-up lands was for the heterogeneity of urban growth. For each municipality, seven statistical indices of built-up patches quantified the urban growth, namely the total area (TA) and its rate in the municipal area (TAR), the mean patch size (MPS), the patch density (PD), the largest patch size (LPS) and its rate (LPR) of total built-up lands, and the standard deviation (SD) of patch size. Transition matrices were developed to quantify the sources of newly developed built-up lands and the inter-conversions among other land use types [41].

\section{Results}

Figure 3 shows the land use maps produced for the PRD of 1990, 2000 and 2010 while Table 4 shows the assessed pixel-to-pixel accuracy and kappa index for each map. The maps present a rapid 
urban expansion process from scattered downtowns to megacities and a significant decrease in land use types of farmland, fishpond and forest.

Table 4. Classification accuracy.

\begin{tabular}{cccc}
\hline & $\mathbf{1 9 9 0}$ & $\mathbf{2 0 0 0}$ & $\mathbf{2 0 1 0}$ \\
\hline Overall accuracy & $83.98 \%$ & $85.94 \%$ & $86.72 \%$ \\
Kappa index & 0.80 & 0.83 & 0.84 \\
\hline
\end{tabular}

Figure 3. Land use maps for 1990 (a), 2000 (b) and 2010 (c), and the quantitative changes of each land use type (d(1)) and the variation of built-up lands among different patch sizes $(\mathbf{d}(\mathbf{2}))$.
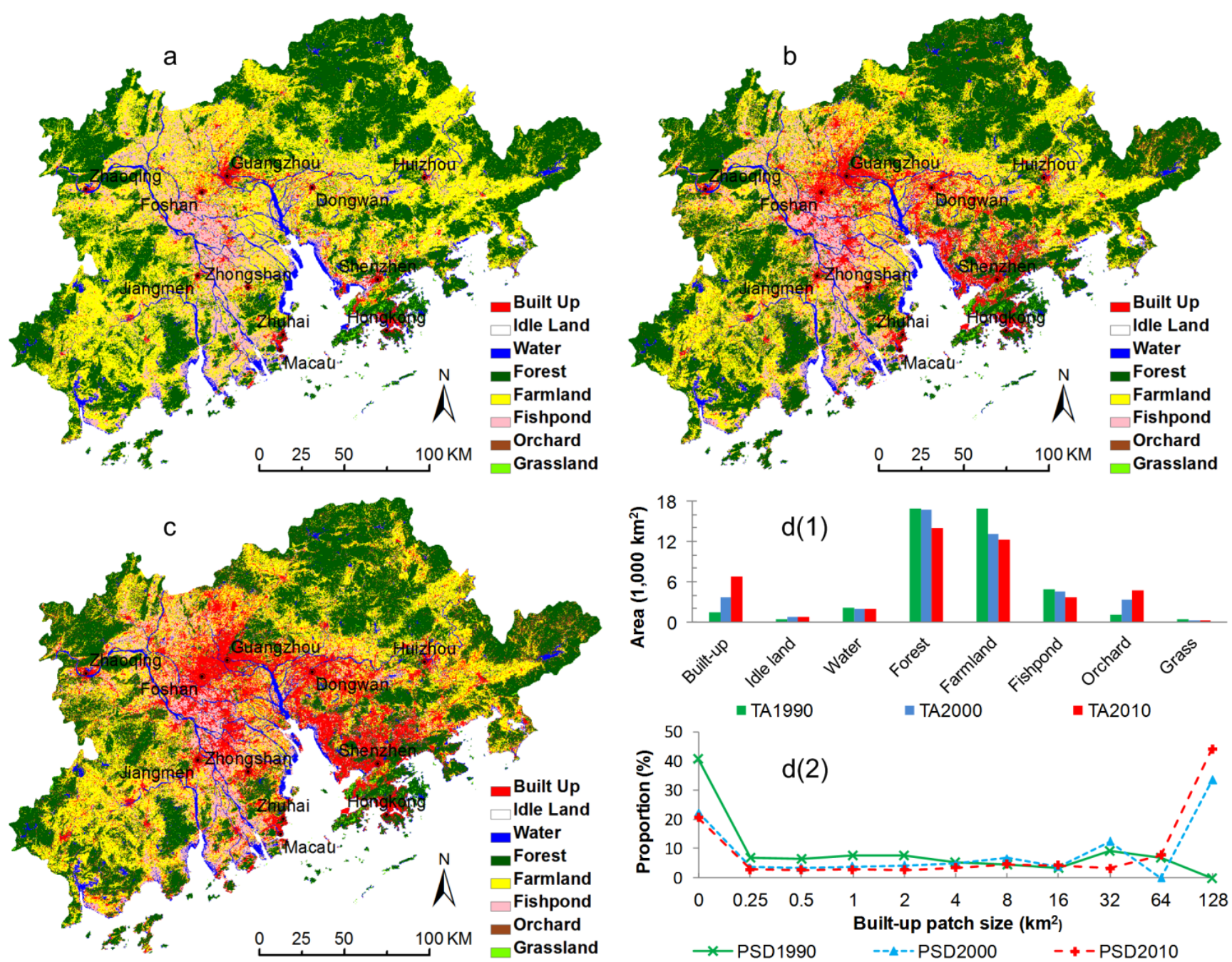

\subsection{Urban Sprawl}

In 1990, the built-up land had an area of only $1,605 \mathrm{~km}^{2}$ and a proportion of $3.56 \%$; however, it more than quadrupled and the proportion reached $15.18 \%$ by 2010 (Figure $3 \mathrm{~d}(1)$ ). The results indicated that the PRD region had already been among the most densely urbanized regions worldwide and comparable to highly urbanized European countries such as the UK (7.5\% built-up area), the Netherlands (11.5\%) and the Belgium (20\%) [42]. At the same time, the urban growth accelerated to some extent as the 
increase in built-up land rose from 2,234 $\mathrm{km}^{2}$ during 1990s to 2,993 $\mathrm{km}^{2}$ during 2000s (Tables 5 and 6). The PRD area thus experienced an accelerated urban expansion in the past 20 years.

Table 5. Land use conversion during 1990-2000.

\begin{tabular}{|c|c|c|c|c|c|c|c|c|c|}
\hline \multirow{2}{*}{1990} & \multicolumn{8}{|c|}{2000} & \multirow{2}{*}{$\begin{array}{c}\text { Loss } \\
\text { in } 1990 \mathrm{~s} \\
\end{array}$} \\
\hline & Built-Up & Idle Land & Water & Forest & Farmland & Fishpond & Orchard & Grass & \\
\hline Built-up & $1,604.96$ & 0.00 & 0.00 & 0.00 & 0.00 & 0.00 & 0.00 & 0.00 & 0.00 \\
\hline Idle land & 265.52 & 181.57 & 3.97 & 9.09 & 56.80 & 14.91 & 49.07 & 0.23 & 399.59 \\
\hline Water & 54.74 & 25.42 & $2,037.30$ & 24.97 & 80.90 & 26.09 & 12.61 & 1.91 & 226.63 \\
\hline Forest & 76.04 & 46.95 & 3.55 & $15,114.99$ & 507.92 & 6.60 & $1,110.26$ & 69.68 & $1,821.00$ \\
\hline Farmland & $1,474.72$ & 461.39 & 32.80 & $1,141.94$ & $12,260.22$ & 23.04 & $1,565.80$ & 9.00 & $4,708.69$ \\
\hline Fishpond & 324.97 & 42.47 & 3.18 & 47.49 & 14.29 & $4,521.53$ & 20.56 & 0.19 & 453.16 \\
\hline Orchard & 37.55 & 25.56 & 1.08 & 270.43 & 339.20 & 1.85 & 533.96 & 9.31 & 684.99 \\
\hline Grass & 0.77 & 0.78 & 0.62 & 194.54 & 14.97 & 0.13 & 44.62 & 217.56 & 256.43 \\
\hline Gain in 1990s & $2,234.31$ & 602.56 & 45.20 & $1,688.45$ & $1,014.08$ & 72.63 & $2,802.93$ & 90.33 & \\
\hline
\end{tabular}

Table 6. Land use Conversion during 2000-2010.

\begin{tabular}{ccccccccccc}
\hline \multirow{2}{*}{$\mathbf{2 0 0 0}$} & \multicolumn{9}{c}{$\mathbf{2 0 1 0}$} & \multirow{2}{*}{ Loss } \\
& \cline { 2 - 8 } Built-Up & Idle Land & Water & Forest & Farmland & Fishpond & Orchard & Grass & in 2000s \\
\hline Built-up & $3,839.28$ & 0.00 & 0.00 & 0.00 & 0.00 & 0.00 & 0.00 & 0.00 & 0.00 \\
Idle land & 355.63 & 205.74 & 13.92 & 1.57 & 4.53 & 11.71 & 189.90 & 1.13 & 578.39 \\
Water & 68.11 & 32.59 & $1,920.14$ & 4.77 & 30.23 & 12.55 & 13.57 & 0.55 & 162.37 \\
Forest & $\mathbf{1 3 0 . 3 2}$ & 63.67 & 19.11 & $13,276.72$ & 976.38 & 20.10 & $2,245.99$ & 71.15 & $\mathbf{3 , 5 2 6 . 7 3}$ \\
Farmland & $\mathbf{1 , 5 6 4 . 2 1}$ & 367.43 & 56.75 & 180.15 & $10,656.10$ & 24.75 & 416.91 & 8.01 & $\mathbf{2 , 6 1 8 . 2 0}$ \\
Fishpond & $\mathbf{6 7 3 . 4 5}$ & 127.24 & 4.43 & 17.42 & 31.43 & $3,665.80$ & 73.88 & 0.51 & 928.36 \\
Orchard & $\mathbf{2 0 0 . 9 0}$ & 63.42 & 7.14 & 468.89 & 636.96 & 6.52 & $1,908.36$ & 44.70 & $1,428.53$ \\
Grass & 0.64 & 0.96 & 0.77 & 73.97 & 13.37 & 0.03 & 23.26 & 194.90 & 113.00 \\
Gain in 2000s & 2993.26 & 655.31 & 102.11 & $\mathbf{7 4 6 . 7 6}$ & $\mathbf{1 , 6 9 2 . 8 9}$ & 75.66 & $2,963.51$ & 126.06 & \\
\hline
\end{tabular}

The urban expansion varied among patches of different sizes (Figure 3d(2)). In 1990, small patches of less than $0.25 \mathrm{~km}^{2}$ dominated the built-up lands with a proportion of $41 \%$; by contrast, the largest patch was only $113 \mathrm{~km}^{2}$. After 20 years, however, the largest patches were up to $1,489 \mathrm{~km}^{2}$ in Shenzhen-Hong Kong-Dongguan belt and $1,094 \mathrm{~km}^{2}$ in Guangzhou-Foshan downtowns, respectively. Patches of more than $128 \mathrm{~km}^{2}$ comprised $44 \%$ of the total built-up lands in 2010; meanwhile, the proportion of small patches dropped sharply to $21 \%$. Thus, small patches dominated the built-up lands at the beginning and subsequently they had merged into megacities [43].

This process varied among the municipalities (Figure 4). Overall, every PRD municipality experienced significant urban expansion in the past 20 years, as the growth rate of built-up lands averaged $382 \%$ and ranged from $192 \%$ in Zhuhai to $749 \%$ in Huizhou. In contrast, the growth rate was only $65 \%$ and $56 \%$ in Hong Kong and Macau, respectively. The landscape metrics categorized the urbanization process in the PRD into three stages, which all were less mature than that in Hong Kong and Macau. In the first stage, presented by Huizhou, Jiangmen, Zhaoqing and Zhuhai, new small centers developed rather than existing centers expanding so that the PD increased strongly while the MPS increased moderately. The LPS did not increase significantly, the LPR even declined and the SD 
was much lower and did not increase notably. Foshan, Guangzhou and Zhongshan showed another stage of urbanization whereby new small urban centers still developed and existing centers expanded outside that resulted in a strong increase in all the five indices. Shenzhen and Dongguan characterized as the third stage whereby urban patches started to merge into larger patches and resulted in a decrease in the PD and an increase in the MPS, LPS, LPR and SD.

Figure 4. Variation of patch indices for built-up land in municipalities. (a) total area and rate; (b) average patch size (APS) and patch density (PD); (c) maximum patch size (MPS) and its rate (MPR) in the total built-up land; and (d) standard deviation (SD) of patch size.
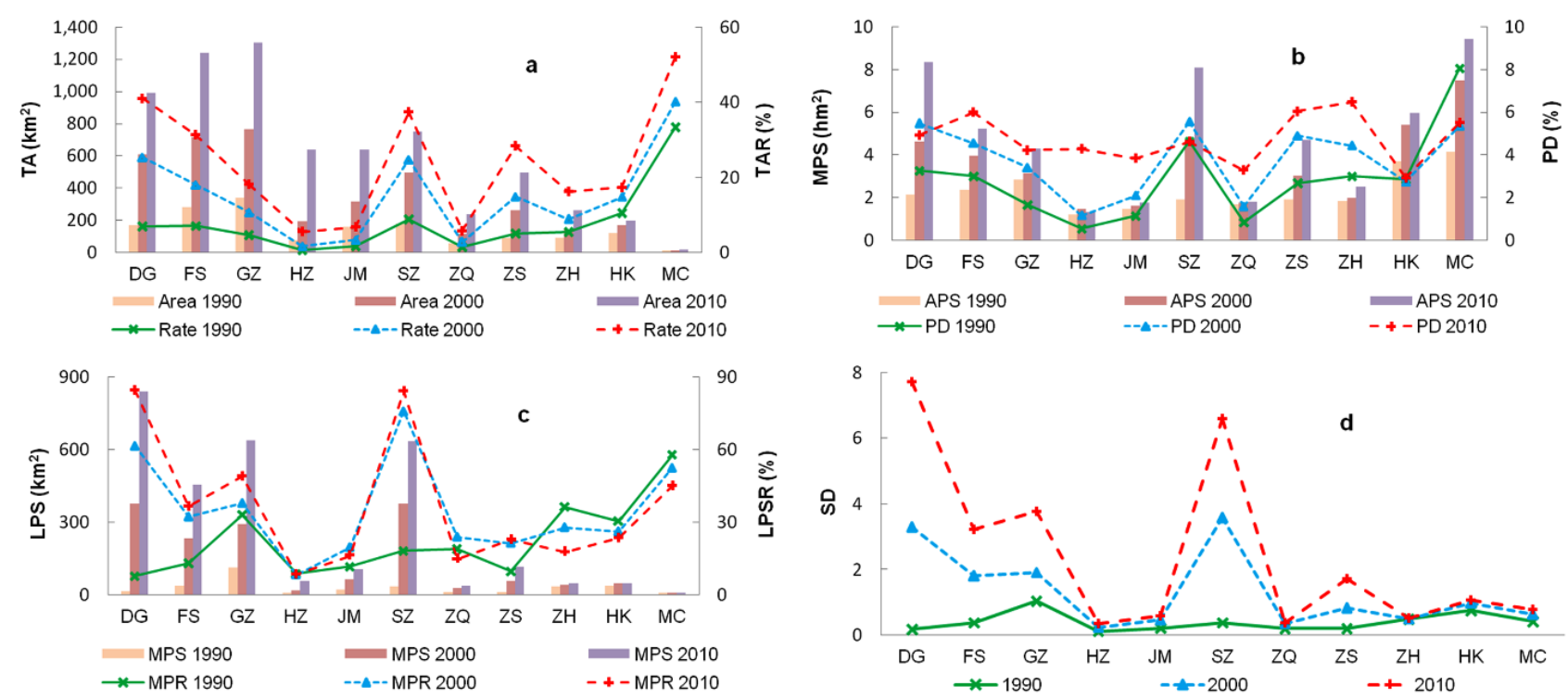

By contrast, Hong Kong and Macau presented examples of the most mature urban growth. In those examples, the PD and LPR declined slightly whereas the MPS, LPS and SD increased slowly, indicating the urban sprawl was relatively controlled in Hong Kong and Macau. Urban population density in Hong Kong and Macau was double that in the PRD in 1990 and then it reached about four times that in the PRD in 2010 (Table 7). Therefore, the population density in the PRD was much lower than that in Hong Kong and Macau and the difference had magnified in the past two decades.

Table 7. The population density ratio (PRD) of Hong Kong (HK) and Macau (MC) vs. the PRD.

\begin{tabular}{cccc}
\hline Population Density Ratio & $\mathbf{1 9 9 0}$ & $\mathbf{2 0 0 0}$ & $\mathbf{2 0 1 0}$ \\
\hline HK/PRD & 2.90 & 3.32 & 4.13 \\
MC/PRD & 1.88 & 2.7 & 3.74 \\
\hline
\end{tabular}

\subsection{Displacement of Farmland to the Surroundings}

As a long-time important production base for rice, sugar cane and tropical fruits in China, the PRD area was once dominated by open space related to farming activities [34]. Figure 3, however, depicts a significant decrease in land use types of farmland, fishpond and forest. According to Figure $3 \mathrm{~d}(1)$, farmland decreased by $3,695 \mathrm{~km}^{2}$ during 1990s; this number dropped to $925 \mathrm{~km}^{2}$ during 2000s. Farmland was consistently the major source of new built-up lands in 1990s and 2000s (Tables 5 and 6) 
by $1,475 \mathrm{~km}^{2}$ and $1,564 \mathrm{~km}^{2}$, respectively. Thus, the net loss of farmland decreased significantly whereas its conversion to built-up land accelerated to a certain extent.

Farmland protection further affected other land use types because of the unchanged preference of urban development on farmland and the significant decline of the net loss of farmland. Overall, the conversion from farmland to forest decreased from $1,142 \mathrm{~km}^{2}$ during $1990 \mathrm{~s}$ to $180 \mathrm{~km}^{2}$ during 2000s while the counter-conversion increased from $508 \mathrm{~km}^{2}$ to $976 \mathrm{~km}^{2}$ (Tables 5 and 6). Consequently, the forest showed a moderate decrease of $133 \mathrm{~km}^{2}$ during 1990s and a dramatic decrease of up to $2,780 \mathrm{~km}^{2}$ during 2000s. Spatially, the forest decreased notably in all the PRD counties in 2000s whilst it decreased moderately or even increased in some peripheral counties in 1990s. In contrast, farmland declined notably in all the PRD counties during 1990s but increased in the peripheral counties of the West (Zhaoqing, Foshan, Jiangmen) and the Northeast (Guangzhou, Huizhou) during 2000s (Figure 5). There was thus a process of farmland displacement and deforestation from 2000 onwards.

\section{Discussions}

The results presented above are mainly based on remote sensing studies. It is clear that maps produced through image classification cannot be completely error-free. However, validation of land use maps shows an average accuracy of more than $84 \%$. Moreover, the detected land use change results agree with other reports for the PRD on built-up land growth by Ye et al. [44] and on farmland displacement by Zhang, Ma and Wang [25]. Additionally, the process of urbanization acceleration and farmland displacement can also be found in studies of the Yangtze River Delta [45]. Thus, the remote sensing detected processes of urbanization acceleration and farmland displacement in the PRD are in consistent with other studies; moreover, the complex relationships between the two processes have been investigated by means of spatial analysis.

The results reveal that the two processes are indeed combined through complex mechanisms (Figure 6). In order to control urban sprawl and protect farmland, the Basic Farmland Protection Regulation (BFPR) and the Land Administration Law (LAL) have been adopted from 1999 [19,20,46]. They require stakeholders to control the growth of urban lands by using them more efficiently and development on farmlands is only allowed if their substitutes can be reclaimed elsewhere. The two policies are supposed to have two consequences. First, the increase in built-up land would reduce to some extent; second, developers would change the preference of developing on lands from farmlands to others. However, both the two hypotheses are refused as the increase in built-up land has accelerated and it has been consistently dominantly from farmland. Besides, the unchanged preference of accelerated urban expansion on farmlands and the effects to keep farmland stability cause farmland displacement and deforestation. Thus, urban growth has the priority over farmland protection that seems unavoidable in current social-economic condition.

The urban sprawl is primarily because of land price difference between rural and urban lands [47]. The land price in villages is only half or less of that in towns and far below than in cities [48]; the considerable differences encourages small industries to install in villages and towns, especially at the beginning. Also due to the land price difference [47], cities prefer to spread towards rural surroundings rather than improve the efficiency of existing urban lands. Moreover, the land conversion from agricultural use to urban use could enormously increase the land value that mainly becomes 
governments' revenue $[2,28,49]$. In some cities, this revenue could account for $30 \%-70 \%$ of governments' financial income [2], which would probably be invested in industrial facilities and infrastructure to promote the GDP growth and consequently the urban sprawl. It is thus difficult to control urban sprawl since lands of relatively low price are essential for attracting industrial investments [47] and land development is significant in increasing governments' revenue [2].

Figure 5. Relative land use change at county level in (a) built up; (b) farmland; (c) forest; and (d) fishpond.
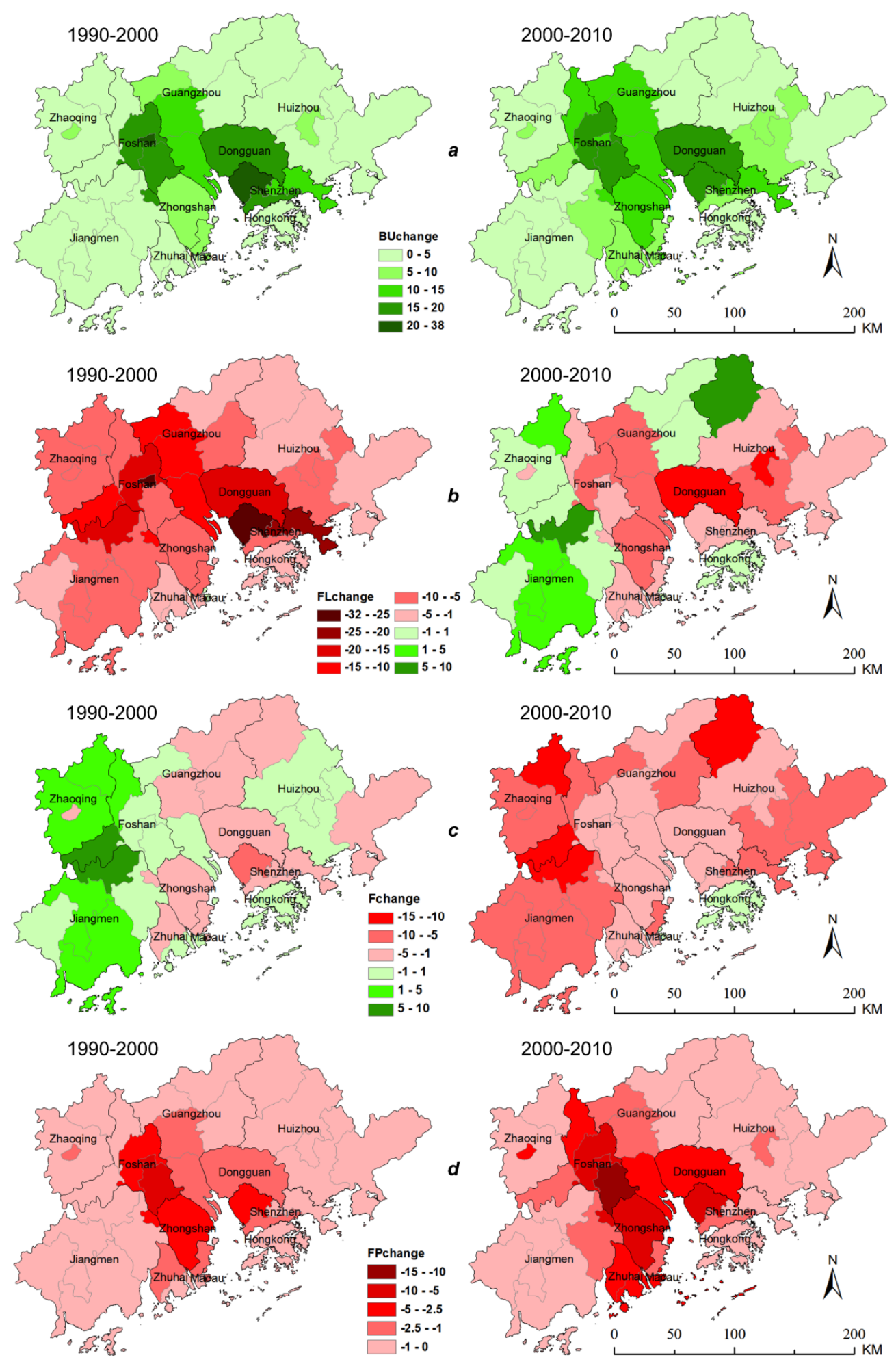
Urban sprawl is further out of control due to inefficient land use planning [2,21,49,50]. In China, government controls the supply of land as the public is the official owner but local government is the manager in practice $[2,19]$. At the same time, land use planning is approved and implemented by the government itself with limited public participation [50]. Government is thus a combination of manager, planner and supervisor [28]. Consequently, land use planning is far less than well implemented and urban expansion always oversteps planned quantity [50] in the context of excessive pursuit for economic growth. Therefore, the conflict between urbanization and farmland protection $[2,21]$ is simply resolved by farmland displacement.

Figure 6. The land use change mechanism and possible solution.

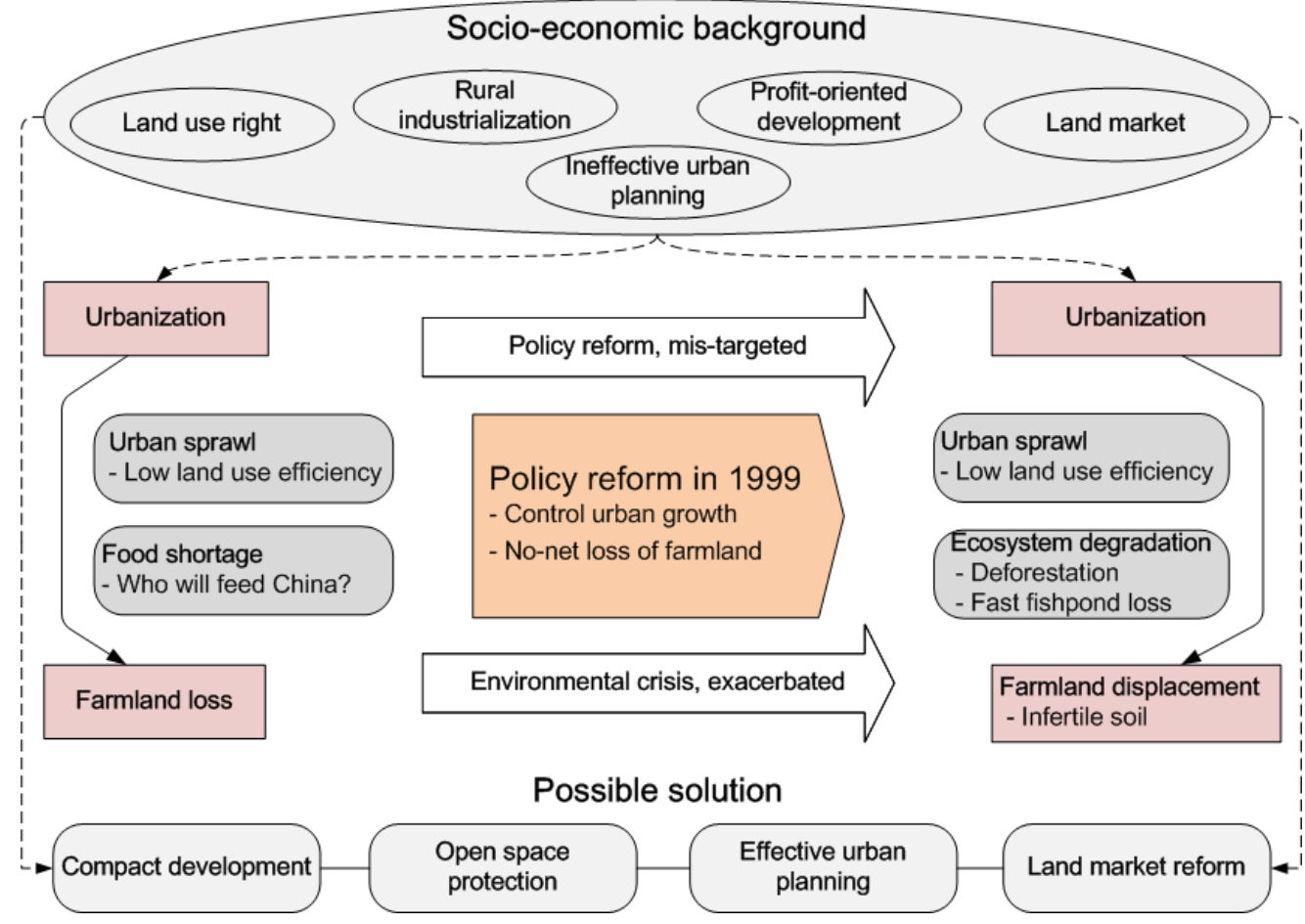

However, the newly reclaimed farmland is mainly on steeper slope and shallower soil that is unlikely to ensure grain production. Averagely, the new farmland pixels are 7.7 degrees in slope and $80.3 \mathrm{~m}$ in elevation during 2000s whereas the levels for their disappeared counterparts are just 2.6 degrees and $14.9 \mathrm{~m}$, respectively. Therefore, the average productivity on the new farmland would probably be lower than on its original counterpart, which partially causes the significant decrease in grain yields from 4.6 million tons to 2.2 million tons during 2000s [51,52]. Nonetheless, the relative decrease in total grain production is much higher than that of farmland area (Figure 7) even in the central PRD counties where very limited new farmland has been reclaimed and grain production mainly takes place on existing older farmland. It thus implies that farmers have diversified the agricultural structure from food grain production to market-oriented farming activities such as livestock husbandry, orchards and vegetables [32,49]. Regarding fruits and vegetables, per capita production rises from $53 \mathrm{~kg}$ and $156 \mathrm{~kg}$ to $152 \mathrm{~kg}$ and $319 \mathrm{~kg}$ in the past decade, respectively [52].

To control urban expansion and protect open space, Hong Kong could be a good example as it controls urban sprawl relatively well while experiencing significant population growth and economy 
development. In this process, effective land use planning plays a critical role through public participation and separation of making and implementing land use plan [50]. Nonetheless, Hong Kong has actually promoted the urban sprawl process in the PRD through industrial relocation and investment. Nowadays, rising land prices and labor shortage in the PRD are pushing away low-profit industries to other areas [53]. These areas will probably face the same conflict between economic development by urban expansion and farmland protection against urban sprawl that once occurred in the PRD. The new host areas should learn from the experiences of the PRD and plan their industrial sites and urban land use accordingly.

Figure 7. Relationship between relative change in grain yield and relative change in farmland area.

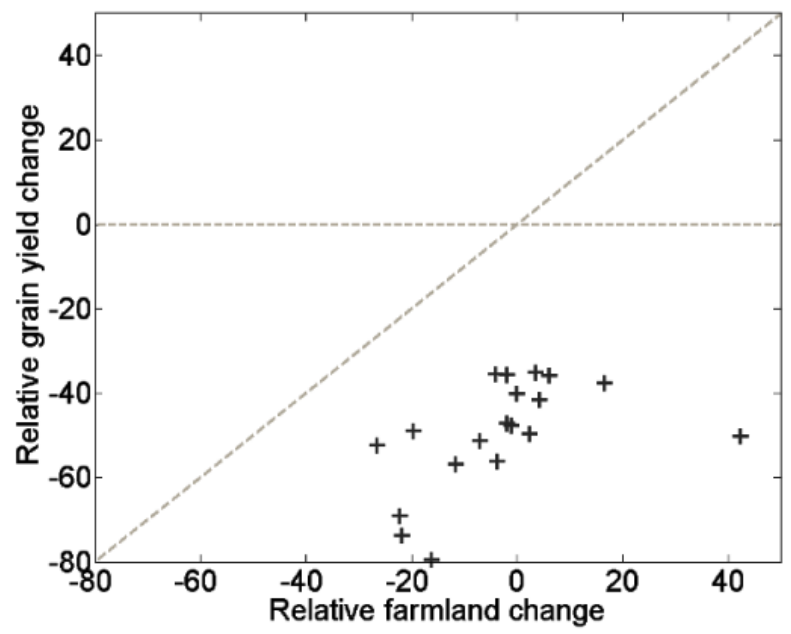

\section{Conclusions}

This paper examined the landscape change and its driving forces in the rapidly urbanized area of the Pearl River Delta (PRD) and its neighboring Hong Kong-Macau, China, based on compiled land use maps for 1990, 2000 and 2010. The land use maps are relatively accurate according to both the point-to-point validation and comparison with other studies $[25,44,45]$. The accuracy was ensured by the relative high resolution Landsat imagery and the classification procedure. In imagery classification, image segmentation was employed to divide the vegetation areas into five sub-areas by means of topographic attributes. It is a useful method in analyzing Remote Sensing data because it can divide the image into homogeneous sub-areas and be able to reduce the image's complexity [37]. It is very suitable to be applied in vegetation classification because vegetation is often heterogeneous due to multiple plant types and densities, and different irrigation and harvest seasons. Landscape metrics were employed in analyzing the urban expansion variation over time and space. Additionally, spatial analysis and statistical data were used to investigate the impact of urban expansion on farmland reclamation and deforestation, and the relationship between farmland change and grain production variation. These quantitative methods precisely revealed the conflicts between urban expansion and farmland protection, and thus have the potential to assistant land use planning.

Urban sprawl has accelerated in the past 20 years due to the profit-oriented development and inefficient land use planning, despite huge concern for farmland protection and urban sprawl control. 
In addition, the conflict between economic growth and farmland protection [2,21] has been simply addressed by dislocating farmland to unsuitable lands. Moreover, the farmland displacement does not ensure the stability of grain production but further causes deforestation. Urban sprawl is actually encouraged at present because encroaching farmlands is relatively cheap and concerned governments could benefit from this process [2,21,27]. A revision of current land policies should therefore focus on stimulating more efficient urban land use. Such stimuli could come from taxation of urban development on farmlands [27]. It may be more effective if the revenue from the tax and the incremental land value could be used for open space protection and as subsidies to ecological agriculture [54]. On the other hand, an ecological agriculture and open space protection system is vital to China's sustainable development as people are increasingly worried about food pollution [55]. This system could thus encourage public awareness and promote wide participation in open space protection and sustainable rural development.

\section{Acknowledgments}

Work performed by the editorial office and the two anonymous referees is greatly acknowledged, and their comments and suggestions have significantly improved this manuscript. The paper is supported by the National Basic Research Program of China (973 Program) (Grant No. 2012CB955404). Thanks to Xiangyue Huang and Bin Xun for their contributions in fieldwork, and to Juan Du for her help in improving the language.

\section{Conflicts of Interest}

The authors declare no conflict of interest.

\section{References}

1. Ding, C.R.; Lichtenberg, E. Land and urban economic growth in China. J. Reg. Sci. 2011, 51, 299-317.

2. Bai, X.; Chen, J.; Shi, P. Landscape urbanization and economic growth in China: Positive feedbacks and sustainability dilemmas. Environ. Sci. Technol. 2012, 46, 132-139.

3. Millennium Ecosystem Assessment. Ecosystems and Human Well-Being: Synthesis; Island Press: Washington, DC, USA, 2005.

4. Bunce, M. Thirty years of farmland preservation in North America: Discourses and ideologies of a movement. J. Rural Stud. 1998, 14, 233-247.

5. Bergstrom, J.C.; Ready, R.C. What have we learned from over 20 years of farmland amenity valuation research in North America? Rev. Agric. Econ. 2009, 31, 21-49.

6. Benedict, M.A.; McMahon, E.T. Green infrastructure: Smart conservation for the 21th Century. Renew. Resour. 2002, 20, 12-17.

7. Ahern, J. Greenways as a planning strategy. Landsc. Urban Plan. 1995, 33, 131-155.

8. Lockhart, J. Green infrastructure: The strategic role of trees, woodlands and forestry. Arboric. $J$. 2009, 32, 33-49.

9. Brueckner, J.K. Urban sprawl: Diagnosis and remedies. Int. Reg. Sci. Rev. 2000, 23, 160-171. 
10. Grimm, N.B.; Faeth, S.H.; Golubiewski, N.E.; Redman, C.L.; Wu, J.G.; Bai, X.M.; Briggs, J.M. Global change and the ecology of cities. Science 2008, 319, 756-760.

11. United Nations (UN). World Urbanization Prospects: The 2011 Revision; No. 0956-2478; United Nations-Department of Economic and Social Affairs/Population Division: New York, NY, USA, 2012.

12. National Bureau of Statistics of China. China Statistical Yearbook 2011; China Statistics Press: Beiijing, China, 2012 (in Chinese).

13. Yusuf, S.; Saich, T. China Urbanizes: Consequences, Strategies, and Policies; The World Bank: Washington, DC, USA, 2008.

14. Brown, L.R. Who Will Feed China? Wake-up for a Small Planet; WW Norton \& Company: New York, NY, USA, 1995.

15. Seto, K.C.; Kaufmann, R.K.; Woodcock, C.E. Landsat reveals China's farmland reserves, but they're vanishing fast. Nature 2000, 406, 121.

16. Tan, M. Urbanization in China: Critical issues in an era of rapid growth. Land Use Policy 2009, $26,856$.

17. Liu, J.Y.; Liu, M.L.; Tian, H.Q.; Zhuang, D.F.; Zhang, Z.X.; Zhang, W.; Tang, X.M.; Deng, X.Z. Spatial and temporal patterns of China's cropland during 1990-2000: An analysis based on Landsat TM data. Remote Sens. Environ. 2005, 98, 442-456.

18. Deng, X.Z.; Huang, J.K.; Rozelle, S.; Uchida, E. Cultivated land conversion and potential agricultural productivity in China. Land Use Policy 2006, 23, 372-384.

19. Lichtenberg, E.; Ding, C.G. Assessing farmland protection policy in China. Land Use Policy 2008, 25, 59-68.

20. LAL Land Administration Law of the P.R. China. Available online: http://www.fdi.gov.cn/ pub/FDI_EN/Laws/GeneralLawsandRegulations/BasicLaws/P020060620320252818532.pdf (accessed on 6 August 2012).

21. Lin, G.C.S. Reproducing spaces of chinese urbanisation: New city-based and land-centred urban transformation. Urban Stud. 2007, 44, 1827-1855.

22. Li, X. Change of arable land area in China during the past 20 years and its policy implicationsChin. J. Nat. Resour. 1999, 14, 329-333 (in Chinese).

23. Liu, J.Y.; Zhang, Z.X.; Xu, X.L.; Kuang, W.H.; Zhou, W.C.; Zhang, S.W.; Li, R.D.; Yan, C.Z.; $\mathrm{Yu}, \mathrm{D} . \mathrm{S}$;; Wu, S.X.; et al. Spatial patterns and driving forces of land use change in China during the early 21 st century. J. Geogr. Sci. 2010, 20, 483-494.

24. Wang, J.; Chen, Y.; Shao, X.; Zhang, Y.; Cao, Y. Land-use changes and policy dimension driving forces in China: Present, trend and future. Land Use Policy 2011, 29, 737-749.

25. Zhang, H.; Ma, W.C.; Wang, X.R. Rapid urbanization and implications for flood risk management in hinterland of the Pearl River Delta, China: The Foshan study. Sensors 2008, 8, 2223-2239.

26. Lu, X.; Huang, S. Barriers and solutions to China's cultivated land protection. Int. J. Environ. Stud. 2010, 67, 223-232.

27. Wei, Y.; Zhao, M. Urban spill over vs. local urban sprawl: Entangling land-use regulations in the urban growth of China's megacities. Land Use Policy 2009, 26, 1031-1045. 
28. Tan, R.; Qu, F.T.; Heerink, N.; Mettepenningen, E. Rural to urban land conversion in China-How large is the over-conversion and what are its welfare implications? China Econ. Rev. 2011, 22, 474-484.

29. Zhong, T.-Y.; Huang, X.-J.; Zhang, X.-Y.; Wang, K. Temporal and spatial variability of agricultural land loss in relation to policy and accessibility in a low hilly region of southeast China. Land Use Policy 2011, 28, 762-769.

30. Taubenbock, H.; Esch, T.; Felbier, A.; Wiesner, M.; Roth, A.; Dech, S. Monitoring urbanization in mega cities from space. Remote Sens. Environ. 2012, 117, 162-176.

31. Liu, J.Y.; Zhang, Q.; Hu, Y.F. Regional differences of China's urban expansion from late 20th to early 21 st century based on remote sensing information. Chin. Geogr. Sci. 2012, 22, 1-14.

32. Lin, G.C.S. Metropolitan development in a transitional socialist economy: Spatial restructuring in the Pearl River Delta, China. Urban Stud. 2001, 38, 383-406.

33. Ouyang, T.P.; Kuang, Y.Q.; Hu, Z.Y.; Sun, B. Urbanization in the pearl river delta economic zone, China. Int. J. Sustain Dev. World 2005, 12, 48-54.

34. Li, X. Measurement of rapid agricultural land loss in the Pearl River Delta with the integration of remote sensing and GIS. Environ. Plan. B Plan. Des. 1998, 25, 447-461.

35. Small, C. A global analysis of urban reflectance. Int. J. Remote Sens. 2005, 26, 661-681.

36. $\mathrm{Xu}, \mathrm{H} . \mathrm{Q}$. Modification of normalised difference water index (NDWI) to enhance open water features in remotely sensed imagery. Int. J. Remote Sens. 2006, 27, 3025-3033.

37. Gupta, R.P. Remote Sensing Geology; Springer Verlag: Berlin/Heidelberg, Germany, 2003; p. 655.

38. Deng, Y.X.; Chen, X.F.; Chuvieco, E.; Warner, T.; Wilson, J.P. Multi-scale linkages between topographic attributes and vegetation indices in a mountainous landscape. Remote Sens. Environ. 2007, 111, 122-134.

39. Botequilha Leitão, A.; Ahern, J. Applying landscape ecological concepts and metrics in sustainable landscape planning. Landsc. Urban Plan. 2002, 59, 65-93.

40. Li, H.B.; Wu, J.G. Use and misuse of landscape indices. Landsc. Ecol. 2004, 19, 389-399.

41. Cousins, S.A.O. Analysis of land-cover transitions based on 17th and 18th century cadastral maps and aerial photographs. Landsc. Ecol. 2001, 16, 41-54.

42. Poelmans, L.; van Rompaey, A. Detecting and modelling spatial patterns of urban sprawl in highly fragmented areas: A case study in the Flanders-Brussels region. Landsc. Urban Plan. 2009, 93, 10-19.

43. Li, L.X.; Wen, F.H.; Xu, X.Q. Urban size structure and fractal characteristics of PRD since implementing the reform \& open policy. Chin. J. Trop. Geogr. 2007, 27, 239-244 (in Chinese).

44. Ye, Y.Y.; Zhang, H.O.; Xu, X.Q.; Zhou, C.S. Study on the relationship between construction land expansion and economic growth in the Pearl River Delta. Chin. J. Geogr. Res. 2011, 12, 2259-2271 (in Chinese).

45. Xu, Y.P. Impacts of Urbanization on River Networks and Hydrology in the Yangtze River Delta (in Chinese); China Science Press: Beijing, China, 2012; p. 238.

46. DLRGP. The Protection Regulations on Basic Farmland of Guangdong Province (in Chinese). Available online: http://www.gdlr.gov.cn/newsAction.do?method=viewNews\&classId=02001035 0000000614\&newsId=020010040000011283 (accessed on 6 August 2012). 
47. Yan, X.P.; Shan, Z.C.; Deng, S.W.; Chen, H.G. Development of commodity housing in Guangzhou and its surrounding areas. Chin. J. Acta Geogr. Sin. 2001, 56, 569-579 (in Chinese).

48. Liu, Y.Y.; Yan, X.P.; Gong, Y.Y. Study on the land management in the central towns of the fast industrialization district. Chin. J. Econ. Geogr. 2006, 26, 643-646 (in Chinese).

49. Wei, K.; Xu, X.Q.; Wei, L.H. Land use change in rural space transition-A case study of Jiaozhong village. Chin. J. Econ. Geogr. 2012, 32, 114-119 (in Chinese).

50. Ng, M.K.; Tang, W.S. Land use planning in a "One Country, Two Systemss": Hong Kong, Guangzhou and Shenzhen. Int. Plan. Stud. 1999, 4, 7-27.

51. Statistics Bureau of Guangdong Province. Guangdong Statistical Yearbook (in Chinese); China Statistic Press: Beijing, China, 2000.

52. Statistics Bureau of Guangdong Province. Guangdong Statistical Yearbook (in Chinese); China Statistic Press: Beijing, China, 2011.

53. Xu, X.Q.; Li, X. Research on the urbanization of Pearl River Delta (1978-2008): Review and preview. Chin. J. Hum. Geogr. 2009, 1, 1-6 (in Chinese).

54. Robinson, G.M. Towards sustainable agriculture: Current debates. Geogr. Compass 2009, 3, 1757-1773.

55. Chen, J. Rapid urbanization in China: A real challenge to soil protection and food security. Catena 2007, 69, 1-15.

(C) 2013 by the authors; licensee MDPI, Basel, Switzerland. This article is an open access article distributed under the terms and conditions of the Creative Commons Attribution license (http://creativecommons.org/licenses/by/3.0/). 